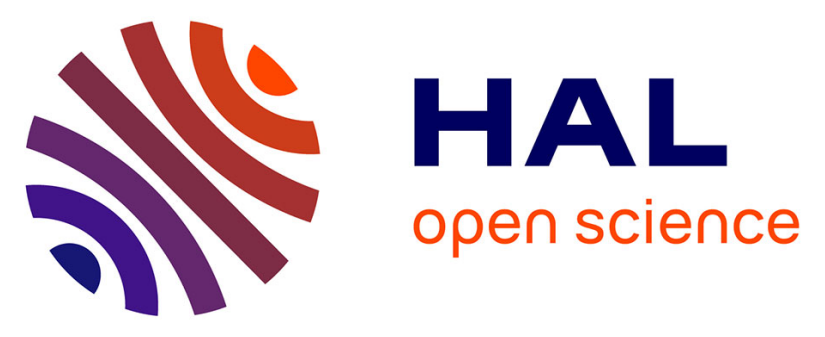

\title{
A Redox-Active Bridging Ligand to Promote Spin Delocalization, High-Spin Complexes, and Magnetic Multi-Switchability
}

Xiaozhou Ma, Elizaveta Suturina, Siddhartha De, Philippe Négrier, Mathieu Rouzières, Rodolphe Clérac, Pierre Dechambenoit

\section{To cite this version:}

Xiaozhou Ma, Elizaveta Suturina, Siddhartha De, Philippe Négrier, Mathieu Rouzières, et al.. A Redox-Active Bridging Ligand to Promote Spin Delocalization, High-Spin Complexes, and Magnetic Multi-Switchability. Angewandte Chemie International Edition, 2018, 57 (26), pp.7841 - 7845. 10.1002/anie.201803842 . hal-01822971

\section{HAL Id: hal-01822971 \\ https://hal.science/hal-01822971}

Submitted on 4 Jul 2018

HAL is a multi-disciplinary open access archive for the deposit and dissemination of scientific research documents, whether they are published or not. The documents may come from teaching and research institutions in France or abroad, or from public or private research centers.
L'archive ouverte pluridisciplinaire HAL, est destinée au dépôt et à la diffusion de documents scientifiques de niveau recherche, publiés ou non, émanant des établissements d'enseignement et de recherche français ou étrangers, des laboratoires publics ou privés.

\section{(1)(1) $\$(0)$}

Distributed under a Creative Commons Attribution - NonCommercial - ShareAlikel 4.0 


\title{
A Redox-Active Bridging Ligand to Promote Spin Delocalization, High-Spin Complexes, and Magnetic Multi-Switchability
}

\author{
Xiaozhou Ma, Elizaveta A. Suturina, Siddhartha De, Philippe Négrier, Mathieu Rouzières, \\ Rodolphe Clérac,* and Pierre Dechambenoit*
}

\begin{abstract}
A$ dinuclear $\mathrm{Co}^{I I}$ complex, $\left[\mathrm{Co}_{2}(\text { tphz })(t p y)_{2}\right]^{n+}(n=$ 4, 3 or 2; tphz: tetrapyridophenazine; tpy: terpyridine), has been assembled using the redox active and strongly complex ing tphz bridging ligand. The magnetic properties of this complex can be tuned from spin crossover with $T_{1 / 2} \approx 470 \mathrm{~K}$ for the pristine compound $(n=4)$ to single molecule magnet with an $S_{T}=5 / 2$ spin ground state when once reduced $(n=3)$ to finally a diamagnetic species when twice reduced $(n=2)$. The two successive and reversible reductions are concomitant with an increase of the spin delocalization within the complex, promoting remarkably large magnetic exchange couplings and high spin species even at room temperature.
\end{abstract}

$\mathrm{O}_{\mathrm{n}}$ materials is the ability to fine tune and control their physical properties by a suitable choice of the molecular compo nents. ${ }^{[1]}$ In magnetism, this ability is of great interest as the magnetic properties usually result from cooperative effects between the spin carriers. The choice of the linker between spin carriers is therefore crucial as it mediates the commu nication/interactions between them. Using redox active bridging ligands is thus particularly appealing as they are able to favor electronic conductivity, provide multistability, and allow a certain tuning of the magnetic properties by simple oxidation or reduction. ${ }^{[2]}$ In particular, the isolation of bridging ligands in their stable radical forms can be seen as the key to design new materials with strong magnetic exchange coupling, as the radical linker acts as a very efficient magnetic relay between the metallic spin carriers. ${ }^{[3]}$ This

[**] X. Ma, Dr. S. De, M. Rouzières, Dr. R. Clérac, Dr. P. Dechambenoit CNRS, CRPP, UMR 5031

33600 Pessac (France),

and

Univ. Bordeaux, CRPP, UMR 5031

33600 Pessac (France)

E mail: clerac@crpp bordeaux.cnrs.fr dechambenoit@crpp bordeaux.cnrs.fr

Dr. E. A. Suturina

School of Chemistry, University of Southampton

Highfield Campus, Southampton, SO17 1BJ (UK)

Dr. P. Négrier

CNRS, LOMA, UMR 5798

33400 Talence (France),

and

Univ. Bordeaux, LOMA, UMR 5798

33400 Talence (France) strategy was successfully used to synthesize single molecule magnets (SMMs), single chain magnets with high blocking temperatures, ${ }^{[3 a c, 4]}$ as well as the first room temperature molecule based magnet. ${ }^{[5]}$

In our quest to design an ideal redox active bridging ligand, tetrapyridophenazine (tphz) has been chosen (Sup porting Information, Scheme S1). This ligand has been reported to be redox active when coordinated to $\mathrm{Ru}$ metal ions, ${ }^{[6]}$ with two successive well separated (by $0.6 \mathrm{~V}$ ) one electron reduction processes. The reduced forms were not further investigated and, to the best of our knowledge, this ligand has never been involved in magnetically interesting materials. The strong coordination ability (thanks to a chelat ing bis(tridentate) coordination mode), the planarity and the extended $\pi$ system of tphz are also expected to support a large delocalization of the unpaired electron when reduced once, providing an excellent radical linker candidate for the design of strongly coupled magnetic architectures. ${ }^{[3 \mathrm{e}]}$ To probe this promising idea, prototype dinuclear complexes have been synthesized by reaction of the bridging tphz ligand with paramagnetic metal centers capped by terpyridine (tpy) blocking ligands. Herein, we report a novel redox active dinuclear $\mathrm{Co}^{\mathrm{II}}$ system, $\left[\mathrm{Co}_{2}(\mathrm{tphz})(\mathrm{tpy})_{2}\right]\left(\mathrm{PF}_{6}\right)_{x}(x=4,3$, or 2$)$, displaying an increasing spin delocalization upon two succes sive reduction processes, resulting in the promotion of remarkably large magnetic couplings, such that the $S_{\mathrm{T}}=5 / 2$ and $S_{\mathrm{T}}=0$ ground states of the mono and twice reduced species remain well isolated from excited states even at room temperature.

$\left[\mathrm{Co}_{2}(\mathrm{tphz})(\mathrm{tpy})_{2}\right]\left(\mathrm{PF}_{6}\right)_{4} \cdot 3 \mathrm{CH}_{3} \mathrm{CN}$ (1) was prepared by reacting $\mathrm{Co}\left(\right.$ tpy) $\mathrm{Cl}_{2}{ }^{[7]}$ with tphz in the presence of $\mathrm{TlPF}_{6}$ in acetonitrile. Subsequent diffusion of diethyl ether vapor into this dark red solution yields needle shaped orange crystals of 1 (see the Supporting Information). This compound was characterized by single crystal X ray diffraction at $120 \mathrm{~K}$ (Figure 1; Supporting Information, Table S1), confirming the envisioned structure with two crystallographically equivalent $\mathrm{Co}(\text { tpy })^{2+}$ units connected by tphz. The complex 1 crystallizes in the $C 2 / c$ space group with a two fold axis passing through its center perpendicularly to the mean plane of the tphz ligand. Each Co ions reside in an octahedral environment involving three nitrogen atoms from the bridging ligand and another three nitrogen atoms from capping terpyridine. The Co $\mathrm{N}$ bond distances between the metal and tpy (Co $\mathrm{N} 4, \mathrm{~N} 5, \mathrm{~N} 6)$ range from 1.87 to $1.99 \AA$, indicating a $\mathrm{Co}^{\mathrm{II}}$ center in its low spin (LS) state. ${ }^{[9]}$ The Co $\mathrm{N}_{\text {pyz }}$ bond distance (Co N2) between Co and tphz is $1.94 \AA$ while the other two Co $\mathrm{N}_{\mathrm{py}}$ distances (Co N1 and Co N3) are significantly longer due to the rigidity of the bridging ligand (Table 1 ). 


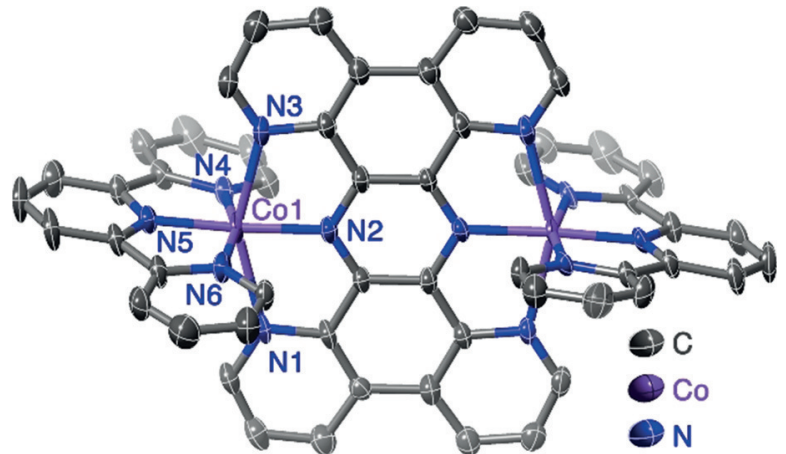

Figure 1. Crystal structure of $\left[\mathrm{Co}_{2}(\mathrm{tphz})(\mathrm{tpy})_{2}\right]^{4+}$ in 1 at $120 \mathrm{~K}$. Ellip soids are set at $50 \%$ probability; hydrogen atoms, solvent molecules, and counteranions are omitted for clarity. ${ }^{[2]}$

Table 1: Selected bond distances $[\AA]$ in 14 complexes.

\begin{tabular}{|c|c|c|c|c|}
\hline & 1 & 2 & 3 & 4 \\
\hline Co N1 & $2.353(6)$ & $2.344(6)$ & $2.396(4)$ & $2.650(4)$ \\
\hline Co N2 & $1.936(5)$ & $1.970(5)$ & $1.923(3)$ & $1.976(5)$ \\
\hline Co N3 & $2.286(6)$ & $2.320(6)$ & $2.269(4)$ & $2.144(4)$ \\
\hline Co N4 & $1.991(6)$ & $2.129(6)$ & $2.152(3)$ & $2.001(4)$ \\
\hline Co N5 & $1.875(5)$ & $2.089(5)$ & $2.069(3)$ & $1.885(4)$ \\
\hline Co N6 & $1.947(6)$ & $2.148(6)$ & $2.128(3)$ & $2.008(4)$ \\
\hline$C \subset(p y z)^{[a]}$ & $1.405(8)$ & $1.397(8)$ & $1.381(6)$ & $1.378(8)$ \\
\hline$C N(p y z)^{[a, b]}$ & $1.331(8)$ & $1.356(8)$ & $1.375(6)$ & $1.392(7)$ \\
\hline $\mathrm{N} 2 \cdots \mathrm{N} 2^{\prime}$ & $2.763(1)$ & $2.821(7)$ & $2.856(4)$ & $2.892(6)$ \\
\hline
\end{tabular}

[a] pyz pyrazine part of tphz. [b] Average distance.

To investigate the redox properties of this prototype dinuclear complex, cyclic voltammetry of $\mathbf{1}$ was performed in acetonitrile, revealing four redox processes, centered at $0.34 \mathrm{~V}, \quad 1.04 \mathrm{~V}, \quad 1.77 \mathrm{~V}$ and $1.93 \mathrm{~V}$ vs. $\mathrm{Fc}^{+} / \mathrm{Fc}$ (Figure 2; Supporting Information, Figure S3). The rest potential is close to $0 \mathrm{~V}$, indicating the presence of only reduction processes, each of them involving one electron. ${ }^{[8]}$ These potentials are very close to what has been reported for the $\mathrm{Ru}$ analogue, ${ }^{[6 \mathrm{~b}]}$ suggesting that the redox processes are mainly centered on the ligands, which will be further confirmed by crystal

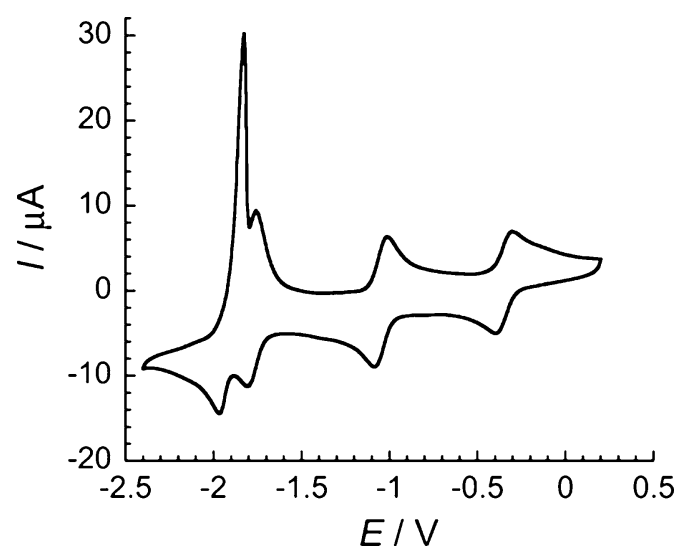

Figure 2. Cyclic voltammogram of a solution of 1 in $\mathrm{CH}_{3} \mathrm{CN}$ at a $0.1 \mathrm{Vs}{ }^{1}$ scan rate, with $0.1 \mathrm{M}\left(n \mathrm{Bu}_{4} \mathrm{~N}\right) \mathrm{PF}_{6}$ as supporting electrolyte. structure analysis and DFT calculations (see below). The first two signals correspond to the reduction of the central tphz whereas those at about $2 \mathrm{~V}$ correspond to those of the tpy ligands. The dissymmetry of the most cathodic signal is very diffusion dependent and was not further investigated. The potentials of the three first reduction processes are well separated (by $0.7 \mathrm{~V}$ ), indicating that the mono and doubly reduced species are particularly stable. It is also remarkable to observe the presence of two peaks for the tpy ligands, indicating a significant electronic coupling through the [Co (tphz)Co] moiety.

Based on these redox properties, 1 was reacted with a slight excess of one, two, and four equivalents of a strong reductant, $\mathrm{KC}_{8}$, affording after recrystallization the once, twice, and four times reduced analogues as $\left[\mathrm{Co}_{2}(\mathrm{tphz})(\mathrm{tpy})_{2}\right]$ $\left(\mathrm{PF}_{6}\right)_{3} \cdot 2 \mathrm{CH}_{3} \mathrm{CN}$ (2), $\left[\mathrm{Co}_{2}(\mathrm{tphz})(\mathrm{tpy})_{2}\right]\left(\mathrm{PF}_{6}\right)_{2} \cdot 2 \mathrm{CH}_{3} \mathrm{CN}$ (3), and $\left[\mathrm{Co}_{2}(\mathrm{tphz})(\mathrm{tpy})_{2}\right] \cdot 2 \mathrm{THF}(\mathbf{4})$. Owing to the extreme instability of $\mathbf{4}$, only its single crystal $\mathrm{X}$ ray analysis is reported in the following.

The overall molecular structure of the dinuclear com plexes in $\mathbf{2}, \mathbf{3}$, and $\mathbf{4}$ is similar to $\mathbf{1}$ (Supporting Information, Figure S1, Table S1); that is, each Co center is surrounded by six nitrogen atoms from tpy and tphz ligands, each Co being equivalent by symmetry as a consequence of an inversion center or two fold axes. Examination of the bond length reveals however noticeable differences and features (Table 1; Supporting Information, Table S2). The average Co $\mathrm{N}$ dis tances between Co and tpy ligands are $2.12 \AA$ in $\mathbf{2}$ and $\mathbf{3}$, consistent with a high spin (HS) $\mathrm{Co}^{\mathrm{II}}$ center. In 4, this average bond distance is $1.96 \AA$ and a clear Jahn Teller distortion is observed along the N1 Co N3 axis, similar to $\mathbf{1}$ and what is expected for a low spin (LS) state. ${ }^{[9]}$ In these complexes, the spin state assignment of the Co sites is also confirmed by DFT (B3LYP/def2 TZVP) calculations, which indicate a LS state significantly lower in energy than the HS state in $\mathbf{1}$ and $\mathbf{4}$, and contrariwise in $\mathbf{2}$ and $\mathbf{3}$ (Supporting Information, Figure S15). This is further supported by ligand field analysis and by the complete active space self consistent field method (CASSCF) carried out in ORCA $4.0,{ }^{[10]}$ which shows that the cobalt centers in $\mathbf{1}$ and $\mathbf{4}$ have larger ligand field splitting than in $\mathbf{2}$ and 3, explaining therefore their LS versus HS preferences (Supporting Information, Figure S16). The possibility to be in presence of $\mathrm{Co}^{\mathrm{III}}$ in $\mathbf{1}$ and $\mathrm{Co}^{\mathrm{I}}$ in $\mathbf{3}$ or $\mathbf{4}$ was also considered, but excluded after combined analysis of the magnetic suscepti bility, crystal structure, and DFT data. Upon reduction, the evolution of $\mathrm{C} \mathrm{N}$ and $\mathrm{C} \mathrm{C}$ bond distances in tpy and tphz ligands (Table 1; Supporting Information, Table S2) is also confirming the previous assignment of the reduction process es. Whereas the two first reductions do not affect the bond distances in the tpy capping ligands, a significant elongation of their $\mathrm{C} \mathrm{N}$ bond distances occurs in $\mathbf{4}$, sign of their reduction in the two most cathodic reduction processes (Supporting Information, Table S2). One can also notice that the two first processes are centered on the pyrazine part of tphz bridging ligand with a significant elongation of pyrazine $\mathrm{C} \mathrm{N}$ bonds and a large increase of $\mathrm{N} 2 \cdots \mathrm{N} 2^{\prime}$ distance, whereas the bond distances of the pyridine moieties in tphz and tpy remain almost unchanged (Table 1). While the Co $\mathrm{N}_{\text {py }}$ distances (Co N1,N3) remain rather long owing to the rigidity of tphz 
in this series of complexes, another interesting structural feature is the remarkably short Co $\mathrm{N}_{\mathrm{pyz}}$ (Co N2) bond distance in $\mathbf{2}(1.97 \AA)$ and even more in $\mathbf{3}$ (1.92 A; Table 1$)$. These bond distances are much shorter than what has been reported for $\mathrm{HS} \mathrm{Co}^{\mathrm{II}}$ centers with similar tetrakis( 2 pyridyl) pyrazine (tppz) ligands. ${ }^{[1]}$ In the present case, the persistently short Co N2 bond length upon reduction is likely a conse quence of the enhanced electrostatic interactions upon successive reductions, which compensate the expected bond lengthening owing to the spin state switching. Those short bond distances also suggest a particularly good overlap between the Co and tphz orbitals, which could enable stronger magnetic exchange coupling than in the tppz based systems, which are already known to mediate significantly strong magnetic coupling. ${ }^{[\mathrm{d}, 11,12]}$

To evaluate and compare the strength of the magnetic coupling in this family of complexes, dc magnetic suscepti bility measurements were performed for $\mathbf{1}, \mathbf{2}$, and $\mathbf{3}$ under a 0.1 T applied field. For $\mathbf{1}$, the $\chi T$ product reaches a plateau at about $100200 \mathrm{~K}$ with a value of $0.85 \mathrm{~cm}^{3} \mathrm{~K} \mathrm{~mol}^{-1}$, in agree ment with two isolated LS $\mathrm{Co}^{\mathrm{II}}$ centers with $g=2.13(5)$ (Figure 3). Upon cooling below $100 \mathrm{~K}$, the $\chi T$ value decreases down to $0.04 \mathrm{~cm}^{3} \mathrm{~K} \mathrm{~mol}^{-1}$ at $1.85 \mathrm{~K}$, which can be ascribed to the presence of an antiferromagnetic coupling between the

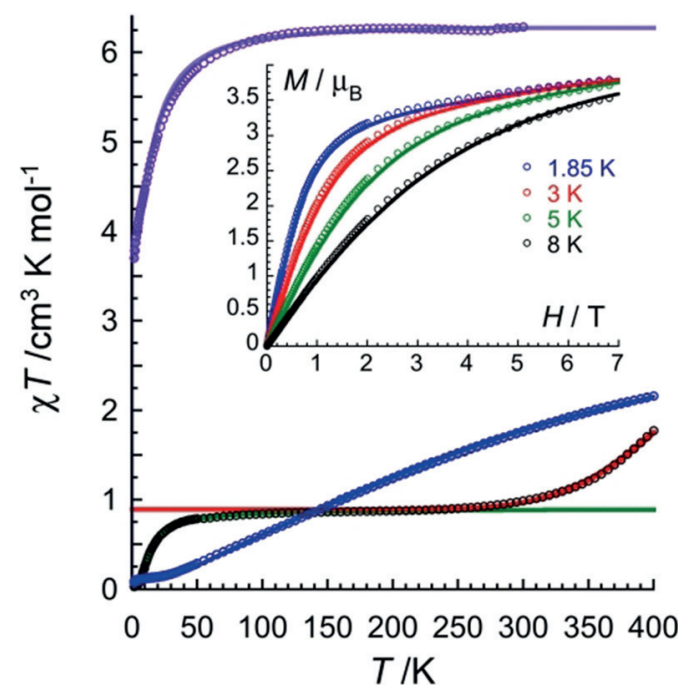

Figure 3. Temperature dependence of the $\chi^{T}$ product for $\mathbf{1}, \mathbf{2}$, and $\mathbf{3}$ at $0.1 \mathrm{~T}$ (black, purple, and blue circles, respectively). The lines represent the best fits as discussed in the text. ${ }^{[13,15,19]}$ Inset: magnetization versus field curves for 2 below $8 \mathrm{~K}$. two $S=1 / 2 \mathrm{Co}^{\mathrm{II}}$ magnetic centers. Although weak, this exchange constant of $12.7(3) \mathrm{K}$ (green line in Figure 3; with $g=2.17(5))^{[13]}$ is remarkably larger than what is usually observed through diamagnetic pyrazine bridging ligand. ${ }^{[3 \mathrm{~g}, 11 \mathrm{~d}]}$ Above $200 \mathrm{~K}$, the compound undergoes a spin crossover (SCO) behavior. The $\chi T$ value at $400 \mathrm{~K}\left(1.72 \mathrm{~cm}^{3} \mathrm{~K} \mathrm{~mol}^{-1}\right)$ highlights an incomplete $S=1 / 2$ (LS) to $3 / 2$ (HS) thermal conversion for each cobalt ion, ${ }^{[14]}$ which was fitted to an ideal solution model (red line in Figure 3) assuming a constant $g$ value of 2.18 and giving rise to $T_{1 / 2} \approx 467(5) \mathrm{K}$ with an associated enthalpy variation of $27(2) \mathrm{kJ} \mathrm{mol}^{-1} \cdot{ }^{[15,16]}$ Upon further cooling, the magnetic properties are nearly reversible but the partial loss of interstitial solvent molecules around $400 \mathrm{~K}$ prevents obtaining the exact same SCO behavior (Supporting Information, Figure S8).

For the monoreduced compound $\mathbf{2}$, the $\chi T$ product found at room temperature is $6.3 \mathrm{~cm}^{3} \mathrm{~K} \mathrm{~mol}^{-1}$, which is much larger than the expected spin only value for two magnetically isolated $S=3 / 2 \mathrm{Co}^{\mathrm{II}}$ and one $S=1 / 2$ radical (Figure 3 ). This result is however more consistent with an $S_{\mathrm{T}}=5 / 2$ ground state (with $g=2.40(5)$ ) expected in presence of an extremely large exchange coupling between $\mathrm{Co}^{\mathrm{II}}$ magnetic centers and the bridging tphz $^{-\cdot}$ radical spin. The $\chi T$ values remain almost constant in the $100300 \mathrm{~K}$ temperature range also indicating that the $S_{\mathrm{T}}=5 / 2$ ground state is well isolated from excited states, as confirmed by DFT calculations that situate the first excited quartet state at about $500 \mathrm{~K}$ above (Supporting Information, Figure S18). The large magnitude of the $J_{\mathrm{Co} \mathrm{tphz}}$. interactions and the resulting temperature independ ence of the $\chi T$ product above $100 \mathrm{~K}$ preclude any exact quantification of $J_{\mathrm{Co} \text { tphz }}$, nevertheless it was roughly esti mated to be at least $500 \mathrm{~K}$ by simulating the experimental susceptibility data using a three spins model with PHI. ${ }^{[17,18]}$ This approximated value constitutes unequivocally one of the highest interaction reported to date ${ }^{[3]}$ and is in good agree ment with DFT results ( $509 \mathrm{~K}$ ). Note that below $300 \mathrm{~K}$, the compound is better described as a single $S_{\mathrm{T}}=5 / 2$ macro spin, with a spin density delocalized on the Co centers, its coordination sphere and the whole pyrazine part of the tphz ligand (Figure 4). The magnetic anisotropy, revealed by the decrease of the $\chi T$ product below $40 \mathrm{~K}$, was estimated to be $D / k_{\mathrm{B}} \approx+27.6(9) \mathrm{K},{ }^{[18,19]}$ in very good agreement with the NEVPT2 results $\left(D / k_{\mathrm{B}}=+27 \mathrm{~K}\right)$.

When further reducing the complex, magnetic suscepti bility measurements of the resulting compound $\mathbf{3}$ reveal a continuous increasing of the $\chi T$ product from $0.07 \mathrm{~cm}^{3} \mathrm{~K} \mathrm{~mol}^{-1}$ at $1.8 \mathrm{~K}$ to $2.01 \mathrm{~cm}^{3} \mathrm{~K} \mathrm{~mol}^{-1}$ at $400 \mathrm{~K}$ without
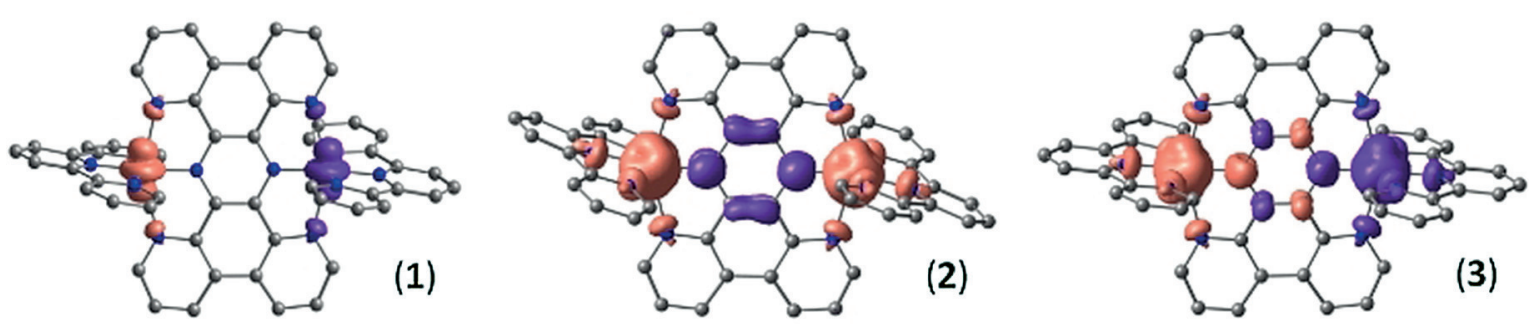

Figure 4. View of the computed spin density of the broken symmetry solution for the complexes in $\mathbf{1}, \mathbf{2}$, and $\mathbf{3}$. Colors represent different signs of the spin density. 
reaching a plateau in this temperature range (Figure 3 ). This thermal behavior is consistent with a strong antiferromagnetic coupling between the two $\mathrm{HS} \mathrm{Co}^{\mathrm{II}}$ magnetic centers leading to a singlet ground state. Indeed, the best fit of the $\chi T$ vs. $T$ data gives rise to $J / k_{\mathrm{B}}=74(5) \mathrm{K}$ (with $g=2.03(5)$; blue line in Figure 3), a much larger coupling than what one could initially expect through a formal diamagnetic ligand. As a conse quence of this large coupling, the singlet ground state is quite well isolated from the excited states, as clearly supported by DFT calculations $\left(J / k_{\mathrm{B}}=137 \mathrm{~K}\right.$, see below $)$. This result is also observed in solution, as confirmed by ${ }^{1} \mathrm{H}$ NMR at room temperature, which shows only slightly paramagnetically shifted resonance peaks of tpy and tphz (between 7.48 .7 and $8.311 .7 \mathrm{ppm}$, respectively; Supporting Information, Fig ure S6), in marked contrast to $\mathbf{1}$ and $\mathbf{2}$ (Supporting Informa tion, Figures S4,S5). The estimation of the magnetic suscept ibility in solution by Evan's method gives rise to a comparable $\chi T$ value at $300 \mathrm{~K}\left(2.48(8) \mathrm{cm}^{3} \mathrm{~K} \mathrm{~mol}^{-1}\right)$ than in solid state $\left(1.77(8) \mathrm{cm}^{3} \mathrm{~K} \mathrm{~mol}^{-1}\right.$; see details in the Supporting Informa tion).

Ac susceptibility measurements were also performed to probe the magnetization dynamics of these complexes and in particular the possible single molecule magnet (SMM) prop erties. ${ }^{[20]}$ Frequency and temperature dependent ac signals were revealed under a small applied dc field (600 Oe; Supporting Information, Figures S9 S12) only for 2. To probe the effect of the applied dc field on the slow relaxation of magnetization, the characteristic time, $\tau$, was extracted by fitting both variable field and temperature ac susceptibility data with the generalized Debye model. The best fit of $\tau(T, H)$ was obtained considering only Direct and Raman relaxation mechanisms (Supporting Information, Figure S13), which are thus at the origin of the SMM properties of $\mathbf{2}^{[21,22]}$

To explain the large intramolecular magnetic interaction and the resulting well isolated ground state of $\left[\mathrm{Co}_{2}(\mathrm{tphz})\right.$ $\left.(\text { tpy })_{2}\right]^{3+}$ and $\left[\mathrm{Co}_{2}(\mathrm{tphz})(\mathrm{tpy})_{2}\right]^{2+}$ in $\mathbf{2}$ and $\mathbf{3}$ respectively, comprehensive DFT studies were performed (see details in the Supporting Information). For both complexes, the spin density calculated with the broken symmetry solution shows a significant spin delocalization on the $\pi$ system of the tphz bridging ligand as depicted on Figure 4. Indeed, as shown by $\mathrm{ab}$ initio ligand field analysis (Supporting Information, Fig ure S16), unpaired electrons of the $\mathrm{HS} \mathrm{Co}^{\mathrm{II}}$ are localized on $\mathrm{d}_{x^{2}-y^{2}}, \mathrm{~d}_{z^{2}}$, and $\mathrm{d}_{x y}$ orbitals. Whereas the $\mathrm{d}_{x^{2}-y^{2}}$ and $\mathrm{d}_{z^{2}}$ orbitals overlap with nitrogen $\sigma$ orbitals, the $d_{x y}$ orbitals interact strongly with $\pi$ orbitals of tphz bridging ligand, providing a privileged channel for significant spin delocalization (Figure 4; Supporting Information, Figures S19 and S20, Table S4), and thus a strong magnetic exchange. This spin delocalization through the $\pi$ system is even slightly larger in $\mathbf{3}$ than in 2 (14 vs. 10\%; Supporting Information, Table S4). These orbital considerations are often overlooked for the design of molecule based magnets except in the case of the cyanide bridge for which this approach has been extensively discussed. ${ }^{[23]}$ As a general synthetic strategy, the present results illustrate the importance of using metal ions with singly occupied $\mathrm{d}_{x y}$ orbital, to design highly magnetically coupled systems with aromatic bridging ligands. The large orbital delocalization is also supported experimentally by a broad absorption band in the NIR region at $782 \mathrm{~nm}$ for $\mathbf{2}$, and $1250 \mathrm{~nm}$ for $\mathbf{3}$ (Supporting Information, Figure S7), indicative of an unusually large electronic delocalization for non mixed valence systems. This ability of the bridging ligand to mediate a strong communication between the metal centers results therefore from a remarkably strong metal ligand coordination (as illustrated by the unusually short Co $\mathrm{N} 2$ bond) intrinsically linked to a strong overlap of $\mathrm{d}$ and $\pi$ orbitals and an extended delocalization through the $\pi$ system.

In summary, a new multi switchable complex has been rationally assembled using a redox active and strongly com plexing bridging ligand. By simple oxidation/reduction, its magnetic properties can be tuned from a spin crossover complex, to a single molecule magnet with an $S_{\mathrm{T}}=5 / 2$ spin ground state (when once reduced) and to diamagnetic species when twice reduced. This work illustrates experimentally and theoretically how successive redox processes can increase the spin delocalization, and thus promote a dramatic enhance ment of the intramolecular magnetic coupling through a bridging ligand, not only in its radical form. This general synthetic approach should help for the intentional design of new high spin complexes and SMMs, but it could also be extended to systems with higher nuclearities and dimension alities, for example to obtain high temperature molecule based magnets.

\section{Acknowledgements}

This work was supported by the ANR (ANR 16 CE29 0001 01, Active Magnet project), the University of Bordeaux, the Région Nouvelle Aquitaine, the CNRS, the MOLSPIN COST action CA15128 and the CSC for the PhD funding of X.M. E.A.S. thanks EPSRC for support (EP/N006895/1), the IRIDIS High Performance Computing Facility and associated services at the University of Southampton and the RSC for a travel grant. The authors thank also D. Woodruff, J. L. Liu, A. Mondal, and S. Exiga for their assistance and fruitful discussions as well as the GdR MCM 2: Magnétisme et Commutation Moléculaires.

\section{Conflict of interest}

The authors declare no conflict of interest.

Keywords: molecular magnetism - multiswitchability · non innocent ligands · radicals · spin delocalization

How to cite: Angew. Chem. Int. Ed. 2018, 57, 78417845 Angew. Chem. 2018, 130, 79677971

[1] Molecular Materials (Eds.: D. W. Bruce, D. O'Hare, R. I. Walton), Wiley, Hoboken, 2010.

[2] D. M. D'Alessandro, Chem. Commun. 2016, 52, 89578971.

[3] a) J. D. Rinehart, M. Fang, W. J. Evans, J. R. Long, J. Am. Chem. Soc. 2011, 133, 14236 14239; b) S. Fortier, J. J. Le Roy, C. H. Chen, V. Vieru, M. Murugesu, L. F. Chibotaru, D. J. Mindiola, K. G. Caulton, J. Am. Chem. Soc. 2013, 135, 14670 14678; c) I. R. Jeon, J. G. Park, D. J. Xiao, T. D. Harris, J. Am. Chem. Soc. 
2013, 135, 16845 16848; d) S. Demir, M. Nippe, M. I. Gonzalez, J. R. Long, Chem. Sci. 2014, 5, 4701 4711; e) J. A. DeGayner, I. R. Jeon, T. D. Harris, Chem. Sci. 2015, 6, 6639 6648; f) S. Demir, I. R. Jeon, J. R. Long, T. D. Harris, Coord. Chem. Rev. 2015, 289 149 176; g) J. O. Moilanen, N. F. Chilton, B. M. Day, T. Pugh, R. A. Layfield, Angew. Chem. Int. Ed. 2016, 55, 5521 5525; Angew. Chem. 2016, 128, 56115615 ; h) J. Wang, J. N. Li, S. L. Zhang, X. H. Zhao, D. Shao, X. Y. Wang, Chem. Commun. 2016 52, 5033 5036; i) B. S. Dolinar, S. Gómez Coca, D. I. Alexan dropoulos, K. R. Dunbar, Chem. Commun. 2017, 53, 22832286 ; j) M. A. Lemes, G. Brunet, A. Pialat, L. Ungur, I. Korobkova, I. Korobkov, M. Murugesu, Chem. Commun. 2017, 53, 86608663 ; k) C. A. Gould, L. E. Darago, M. I. Gonzalez, S. Demir, J. R. Long, Angew. Chem. Int. Ed. 2017, 56, 10103 10107; Angew. Chem. 2017, 129, 10237 10241; 1) S. Demir, M. I. Gonzalez, L. E. Darago, W. J. Evans, J. R. Long, Nat. Commun. 2017, 8 2144; m) B. S. Dolinar, D. I. Alexandropoulos, K. R. Vignesh, T. A. James, K. R. Dunbar, J. Am. Chem. Soc. 2018, 140, 908 911; n) M. A. Lemes, H. N. Stein, B. Gabidullin, K. Robeyns, R. Clérac, M. Murugesu, Chem. Eur. J. 2018, 24, 42594263.

[4] N. Ishii, Y. Okamura, S. Chiba, T. Nogami, T. Ishida, J. Am. Chem. Soc. 2008, 130, 2425 .

[5] J. M. Manriquez, G. T. Yee, R. S. McLean, A. J. Epstein, J. S. Miller, Science 1991, 252, 14151417.

[6] a) P. Bonhôte, A. Lecas, E. Amouyal, Chem. Commun. 1998, 885886 ; b) A. Gourdon, J. P. Launay, Inorg. Chem. 1998, 37, 53365341.

[7] C. M. Harris, T. N. Lookyer, R. L. Martin, H. R. H. Patil, E. Sinn, I. M. Stewart, Aust. J. Chem. 1969, 22, 21052116.

[8] Cyclic voltammograms of $\mathbf{1}, \mathbf{2}$, and $\mathbf{3}$ are identical. Only the rest potential is different, $0.1 \mathrm{~V}$ versus $0.8 \mathrm{~V}$ and $1.1 \mathrm{~V}$ respec tively, confirming the one electron reduction processes (Sup porting Information, Figure S3).

[9] J. England, E. Bill, T. Weyhermüller, F. Neese, M. Atanasov, K. Wieghardt, Inorg. Chem. 2015, 54, 1200212018.

[10] F. Neese, WIREs Comput. Mol. Sci. 2012, 2, 7378.

[11] a) C. S. Campos Fernández, B. W. Smucker, R. Clérac, K. R. Dunbar, Isr. J. Chem. 2001, 41, 207 218; b) E. Burkholder, J. Zubieta, Inorg. Chim. Acta 2005, 358, 116 122; c) G. Y. Hsu, C. W. Chen, S. C. Cheng, S. H. Lin, H. H. Wei, C. J. Lee, Polyhedron 2005, 24, 487 494; d) N. G. Armatas, D. J. Allis, A. Prosvirin, G. Carmutu, C. J. O'Connor, K. Dunbar, J. Zubieta, Inorg. Chem. 2008, 47, 832854.

[12] a) J. Carranza, J. Sletten, C. Brennan, F. Lloret, J. Canoa, M. Julve, Dalton Trans. 2004, 3009 4005; b) M. Graf, H. Stoeckli Evans, A. Escuer, R. Vicente, Inorg. Chim. Acta 1997, 257, 89 97.
[13] $J / k_{\mathrm{B}}$ and $g$ were estimated by fitting the experimental data to the susceptibility calculated from the van Vleck equation in the weak field approximation relative to the following isotropic spin Hamiltonian: $\hat{\mathbf{H}} \quad 2 J\left(\hat{S}_{\mathrm{Co} 1} \hat{S}_{\mathrm{Co} 2}\right)$.

[14] J. Palion Gazda, B. Machura, R. Kruszynski, T. Grancha, N. Moliner, F. Lloret, M. Julve, Inorg. Chem. 2017, 56, 62816296.

[15] The thermal dependence of the spin crossover was fitted to the following equation deduced from the ideal solution model: $\chi T \quad \chi T_{\mathrm{LS}}+\left(\chi T_{\mathrm{HS}} \quad \chi T_{\mathrm{LS}}\right) /\left(1+\exp \left[\Delta H / R\left(1 / T \quad 1 / T_{1 / 2}\right)\right]\right)$ with $\chi T_{\mathrm{LS}}$ and $\chi T_{\mathrm{HS}}$ being the $\chi T$ products for pure LS and HS species assuming a $g$ value of $2.18, R$ the ideal gas constant and $\Delta H$ the associated enthalpy variation.

[16] P. Atkins, J. De Paula, Physical Chemistry, Oxford University Press, Oxford, 2006, chap. 5.

[17] $J / k_{\mathrm{B}}$ was roughly estimated by fitting the data using the following spin Hamiltonian: $\hat{\mathbf{H}} \quad 2 J \hat{S}_{\mathrm{rad}}\left(\hat{S}_{\mathrm{Co} 1}+\hat{S}_{\mathrm{Co} 2}\right)$. The slight increase of the $\chi T$ product between 280 and $300 \mathrm{~K}$ is the onset of the solvent loss, which precludes fully reproducible studies at higher temperatures.

[18] N. F. Chilton, R. P. Anderson, L. D. Turner, A. Soncini, K. S. Murray, J. Comput. Chem. 2013, 34, 11641175.

[19] $g$ and $D$ were estimated by fitting simultaneously the $\chi T$ vs. $T$ and $M$ vs. $H$ data with the Phi software using the following spin Hamiltonian: $\hat{\mathbf{H}} D \hat{S}^{2}$.

[20] M. Murrie, Chem. Soc. Rev. 2010, 39, 19861995.

[21] The relation $\tau^{1} \tau_{\text {Raman }}^{1}+\tau_{\text {Direct }}^{1} \quad C \frac{1+B_{1} H^{2}}{1+B_{2} H^{2}} T^{n}+A T H^{4}$ was used to fit simultaneously the $\tau$ vs. $T$ and $\tau$ vs. $H$ data (see details in the Supporting Information).

[22] a) K. N. Shrivastava, Phys. Status Solidi A 1983, 117, 437 458; b) J. H. van Vleck, Phys. Rev. 1940, 57, 426 447; c) A. Abragam, B. Bleaney, Electron Paramagnetic Resonance of Transition Ions, Dover, New York, 1986; d) A. Singh, K. N. Shrivastava, Phys. Status Solidi B 1979, 95, 273277.

[23] a) M. Verdaguer, A. Bleuzen, V. Marvaud, J. Vaissermann, M. Seuleiman, C. Desplanches, A. Scuiller, C. Train, R. Garde, G. Gelly, C. Lomenech, I. Rosenman, P. Veillet, C. Cartier, F. Villain, Coord. Chem. Rev. 1999, 190 192, 1023 1047; b) E. Ruiz, A. Rodriguez Fortea, S. Alvarez, M. Verdaguer, Chem. Eur. J. 2005, 11, 21352144.

[24] CCDC 15883211588324 contains the supplementary crystallo graphic data for this paper. These data are provided free of charge by The Cambridge Crystallographic Data Centre. 